\title{
Front Matter: Volume 8907
}

, "Front Matter: Volume 8907," Proc. SPIE 8907, International Symposium on Photoelectronic Detection and Imaging 2013: Infrared Imaging and Applications, 890701 (11 September 2013); doi: 10.1117/12.2035268

SDIE Event: ISPDI 2013 - Fifth International Symposium on Photoelectronic SPIE. Detection and Imaging, 2013, Beijing, China 


\title{
International Symposium on Photoelectronic Detection and Imaging 2013
}

\section{Infrared Imaging and Applications}

\author{
Haimei Gong \\ Zelin Shi \\ Qian Chen \\ Jin Lu \\ Editors
}

25-27 June 2013

Beijing, China

Organized by

Photoelectronic Technology Committee, Chinese Society of Astronautics • Tianjin Jinhang Institute of Technical Physics (China) - Science and Technology on Low Light Level Night Vision Laboratory (China) - Science and Technology on Optical Radiation Laboratory (China) - Science and Technology on Electromagnetic Scattering Laboratory (China)

Sponsored by

SPIE • The Optical Society • European Optical Society • Chinese Society of Astronautics

Published by

SPIE

Volume 8907

Proceedings of SPIE 0277-786X, V. 8907

SPIE is an international society advancing an interdisciplinary approach to the science and application of light.

International Symposium on Photoelectronic Detection and Imaging 2013: Infrared Imaging and Applications, edited by Haimei Gong, Zelin Shi, Qian Chen, Jin Lu, Proc. of SPIE Vol. 8907, 890701

(c) 2013 SPIE · CCC code: 0277-786X/13/\$18 · doi: 10.1117/12.2035268 
The papers included in this volume were part of the technical conference cited on the cover and title page. Papers were selected and subject to review by the editors and conference program committee. Some conference presentations may not be available for publication. The papers published in these proceedings reflect the work and thoughts of the authors and are published herein as submitted. The publisher is not responsible for the validity of the information or for any outcomes resulting from reliance thereon.

Please use the following format to cite material from this book:

Author(s), "Title of Paper," in International Symposium on Photoelectronic Detection and Imaging 2013: Infrared Imaging and Applications, edited by Haimei Gong, Zelin Shi, Qian Chen, Jin Lu, Proceedings of SPIE Vol. 8907 (SPIE, Bellingham, WA, 2013) Article CID Number.

ISSN: 0277-786X

ISBN: 9780819497765

Published by

SPIE

P.O. Box 10, Bellingham, Washington 98227-0010 USA

Telephone +1 3606763290 (Pacific Time) · Fax +1 3606471445

SPIE.org

Copyright (C) 2013, Society of Photo-Optical Instrumentation Engineers.

Copying of material in this book for internal or personal use, or for the internal or personal use of specific clients, beyond the fair use provisions granted by the U.S. Copyright Law is authorized by SPIE subject to payment of copying fees. The Transactional Reporting Service base fee for this volume is $\$ 18.00$ per article (or portion thereof), which should be paid directly to the Copyright Clearance Center (CCC), 222 Rosewood Drive, Danvers, MA 01923. Payment may also be made electronically through CCC Online at copyright.com. Other copying for republication, resale, advertising or promotion, or any form of systematic or multiple reproduction of any material in this book is prohibited except with permission in writing from the publisher. The CCC fee code is 0277-786X/13/\$18.00.

Printed in the United States of America.

Publication of record for individual papers is online in the SPIE Digital Library.

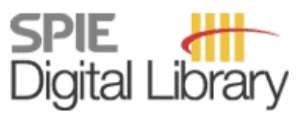

SPIEDigitalLibrary.org

Paper Numbering: Proceedings of SPIE follow an e-First publication model, with papers published first online and then in print and on CD-ROM. Papers are published as they are submitted and meet publication criteria. A unique, consistent, permanent citation identifier (CID) number is assigned to each article at the time of the first publication. Utilization of CIDs allows articles to be fully citable as soon as they are published online, and connects the same identifier to all online, print, and electronic versions of the publication. SPIE uses a six-digit CID article numbering system in which:

- The first four digits correspond to the SPIE volume number.

- The last two digits indicate publication order within the volume using a Base 36 numbering

system employing both numerals and letters. These two-number sets start with 00, 01, 02, 03, 04, $05,06,07,08,09,0 A, 0 B \ldots 0 Z$, followed by 10-1Z, 20-2Z, etc.

The CID Number appears on each page of the manuscript. The complete citation is used on the first page, and an abbreviated version on subsequent pages. Numbers in the index correspond to the last two digits of the six-digit CID Number. 


\title{
Contents
}

\author{
xxi Conference Committee \\ xxiii Introduction
}

\section{Part One}

\section{INFRARED IMAGING AND APPLICATIONS}

890702 Temperature characteristic of InAs/Ga(In)Sb middle wavelength infrared detectors (Invited Paper) [8907-200]

Y. Shi, R. Hui, W.-F. Zhang, W.-J. He, J. Yuan, J.-M. Feng, F. Li, L.-M. Liu, Kunming Institute of Physics (China)

890703 Study on dark current of extended wavelength InGaAs detectors (Invited Paper) [8907-289] X. Li, H. Tang, T. Li, P. Wei, H. Gong, J. Fang, Shanghai Institute of Technical Physics (China)

890704 Progress in the CdZnTe single crystal growth and substrates fabrication (Invited Paper) [8907-311]

S. Sun, C. Zhou, H. Yu, C. Xu, F. Sheng, S. Sui, J. Yang, L. He, Shanghai Institute of Technical Physics (China)

890705 Technologies for thermal infrared imaging from GEO (Invited Paper) [8907-314]

W. Ma, Beijing Institute of Space Mechanics and Electricity (China)

890706 Detector MTF based micro-scanning image reconstruction (Invited Paper) [8907-185]

L. LU, W. Jin, X. Dun, X. Wang, Beijing Institute of Technology (China)

890707 Design of static star simulator based on testing of very high accuracy star sensor [8907-1] Q. Chen, Changchun Univ. of Science and Technology (China); G. Zhang, Changchun Univ. of Science and Technology (China) and Jilin Engineering Research Ctr. of Photoelectric Measurement \& Control Instruments (China); Z. Wang, Changchun Univ. of Science and Technology (China); L. Wang, Changchun Univ. of Science and Technology (China) and Jilin Engineering Research Ctr. of Photoelectric Measurement \& Control Instruments (China); Y. Gao, Changchun Institute of Optics, Fine Mechanics and Physics (China)

890708 The design of real time infrared image generation software based on Creator and Vega [8907-2]

R. Wang, W. WU, J. Huo, PLA Nanjing Artillery Academy (China)

890709 Application of infrared detection in condition-based maintenance for reactive compensation capacitor sets [8907-3]

Q. XU, B. Wang, J. Wang, Suzhou Power Supply Co. (China) 
8907 OA Design of compact apochromatic lens with very-broad spectrum and high resolution [8907-4]

A. Yan, J. Cao, J. Zhang, Z. Zhang, H. Wang, D. Wu, Z. Zhou, K. Zhang, Y. Lei, Xi'an Institute of Optics and Precision Mechanics (China)

8907 OC Infrared small target detection technology based on OpenCV [8907-6]

L. Liu, Z. Huang, Nanjing Univ. of Science and Technology (China)

8907 OD Level set segmentation for greenbelts by integrating wavelet texture and priori color knowledge [8907-7]

T. Yang, Z. Song, C. Jiang, L. Huang, Guilin Univ. of Technology (China)

8907 OE Research on low-power technologies of software in embedded systems [8907-10]

K. Tang, B. Xie, New Star Research Institute of Applied Technology (China)

8907 OF Modeling and simulation of TDI CMOS image sensors [8907-11]

K. Nie, S. Yao, J. Xu, J. Gao, Tianjin Univ. (China)

8907 OG Design and optimization of four-transistor pixel for low image lag CMOS image sensor [8907-12]

C. Xu, J. Xu, S. Yao, J. Gao, Z. Gao, Tianjin Univ. (China)

$8907 \mathrm{OH} \quad$ Stray light suppression of optical and mechanical system for telescope detection [8907-13] L. Wang, Institute of Optics and Electronics (China) and Univ. of Chinese Academy of Sciences (China); W. Ma, Institute of Optics and Electronics (China)

8907 0J A fast image registration algorithm for super-resolution [8907-19]

C. Li, Soochow Univ. (China) and Science and Technology on Electro-optical Security Lab. (China); X. Zhao, K. Lu, Soochow Univ. (China); X. Zhang, Science and Technology on Electro-optical Security Lab. (China)

8907 OK Beam arrangement on two-dimensional temperature reconstruction based on laser absorption spectroscopy [8907-20]

J. Song, Y. Hong, H. Pan, G. Wang, State Key Lab. of Laser Propulsion and Application (China)

$8907 \mathrm{OL}$ The experimental study of weak rough surface characteristic of laser scatter [8907-22] J. Cui, H. Fu, Y. Qian, A. He, Nanjing Univ. of Science and Technology (China)

8907 OM An efficient mosaic algorithm for UAV aerial images in multiple-strips flying [8907-24] J. Wang, Tianjin Univ. (China) and The JinHang Computational Technology Research Institute (China); R. Jia, The JinHang Computational Technology Research Institute (China)

8907 ON Vibration detection and calibration method used to remote sensing optical camera [8907-26]

Q. Li, W. Dong, Z. Xu, H. Feng, Zhejiang Univ. (China) 
890700 A shape context based Hausdorff similarity measure in image matching [8907-27] T. Ma, Shenyang Institute of Automation (China), Key Lab. of Optical-Electronics Information Processing (China), and Univ. of Chinese Academy of Sciences (China); Y. Liu, Z. Shi, Shenyang Institute of Automation (China) and Key Lab. of Optical-Electronics Information Processing (China); J. Yin, The Research Institute on General Development and Argumentation of Equipment of Air Force (China)

$8907 \mathrm{OP}$ Infrared and visible image fusion based on region growing and contourlet transform [8907-28]

B. Zhao, Xi'an Institute of Optics and Precision Mechanics (China) and Univ. Of Chinese Academy of Sciences (China); W. Gao, Z. Song, Xi'an Institute of Optics and Precision Mechanics (China)

$89070 Q$ Research on dual-band image fusion algorithms and simulation based on infrared radiation characteristics [8907-29]

S. Han, P. Zhang, W. Hu, China Electronic Science of Technology Group Co., Ltd. (China)

8907 OR Short to long-wave IR detectors based on InAs/GaSb superlattices in multi-color application [8907-30]

J. Guo, Yunnan Normal Univ. (China); G. Wang, Institute of Semiconductors (China); X. Lin,

R. Hao, Yunnan Normal Univ. (China)

8907 OT Research on infrared imaging illumination model based on materials [8907-32]

$\mathrm{H}$. Hu, Beijing Institute of Technology (China) and Xuchang Vocational Technical College

(China); C. Feng, C. Guo, Xuchang Vocational Technical College (China); H. Zheng,

Q. Han, Beijing Institute of Technology (China); H. Hu, CPCC Culture and History Library (China)

8907 OU Evaluation method based on the image correlation for laser jamming image [8907-33] J. Che, Z. Li, B. Gao, People's Liberation Army (China)

8907 OV Stair phenomenon study in spectrum infrared transmission of water spray [8907-34] Z. Chen, L. Zhang, C. Liang, H. Wang, L. Zhang, Naval Academy of Armament (China)

8907 OW High ratio long-wave infrared continuous zoom system [8907-38] J. Yan, Q. Sun, Changchun Univ. of Science and Technology (China); Y. Liu, H. Zhou, Changchun Institute of Optics, Fine Mechanics and Physics (China); K. Huan, X. Shi, Changchun Univ. of Science and Technology (China)

8907 0X A multi-exposure image fusion method based on wavelet packet transform [8907-39] Q. Wang, Xi'an Institute of Optics and Precision Mechanics (China) and Univ. of Chinese Academy of Sciences (China); Z. Song, W. Gao, Xi'an Institute of Optics and Precision Mechanics (China)

8907 OY An improved image fusion algorithm based on wavelet transform [8907-41] Z. Duan, Xi'an Institute of Optics and Precision Mechanics (China) and Univ. of Chinese Academy of Sciences (China); D. Wen, Z. Song, Xi'an Institute of Optics and Precision Mechanics (China)

$89070 Z$ A novel super resolution scheme to acquire and process satellite images [8907-42] D. Yin, X. Su, J. Lin, G. Wang, D. Kuang, Key Lab. of Infrared System Detection and Imaging Technology (China) and Shanghai Institute of Technical Physics (China) 
890710 Study on an improved filtered back-projection image reconstruction algorithm combined with wavelet denoising [8907-43]

Z. Ren, G. Liu, Z. Huang, Jiangxi Science and Technology Normal Univ. (China)

890711 Detecting and tracking small moving target in infrared image sequence [8907-44]

H. Yan, G. Huang, H. Wang, R. Shu, Shanghai Institute of Technical Physics (China)

890713 Multi scale detail-preserving denoising method of infrared image via relative total variation [8907-46]

G. Cui, H. Feng, Z. Xu, Q. Li, Y. Chen, Zhejiang Univ. (China)

890714 PI film property analysis in the application of infrared image transform technique [8907-47]

Y. Li, L. Zhang, Shanghai Institute of Mechanics and Electricity Engineering (China); Z. Li,

Beijing Institute of Technology (China)

890715 A heating window effect imaging experiment and its analysis [8907-48]

Z. Peng, X. Wang, J. Lu, Tianjin Univ. (China) and Key Lab. of Optical Thin Films (China)

890716 The research of auto-focusing method for the image mosaic and fusion system with multisensor [8907-51]

K. Pang, S. Yao, Z. Shi, J. Xu, J. Liu, Tianjin Univ. (China)

890717 An improved template tracking method based on rigid extended object [8907-52]

J. Zhang, Chengdu Univ. (China) and Univ. of Electronic Science and Technology of China (China); Z. Peng, Univ. of Electronic Science and Technology of China (China)

890718 Research on visible and near infrared spectral-polarimetric properties of snow in different melting states [8907-53]

H. Shen, Anhui Univ. of Architecture (China); P. Zhou, New Star Research Institute of Applied Technology (China)

890719 The analysis of detection probability for active laser detection system [8907-54]

L. Zeng, T. An, Institute of Optics and Electronics (China)

8907 1A Design of lens-hood in the space fisheye optical system [8907-55]

Q. Zhu, Z. Zhang, Z. Zhang, A. Yan, J. Cao, K. Zhang, Xi'an Institute of Optics and Precision Mechanics (China)

8907 IB Design of real-time image processing system for IRFPA based on FPGA [8907-56]

P. Wang, L. Gao, G. Chen, Shanghai Institute of Technical Physics (China) and Univ. of

Chinese Academy of Sciences (China); R. Ding, Shanghai Institute of Technical Physics

(China)

8907 1C Conceptual design of $1.5 \mathrm{~m}$ aperture vertical collimator assembly with short tube and long focus [8907-57]

F. Yang, M. Ming, F. Wang, L. Zhang, B. Chen, L. Shao, Changchun Institute of Optics, Fine Mechanics and Physics (China)

8907 1D The study of the thermal imaging law on several objects in winter environment [8907-61] $X$. Wang, M. Pang, Institute of Chemical Defense (China) 
8907 IE Backward Monte Carlo analysis on stray radiation of an infrared optical system [8907-62] X. Chen, C. Sun, X. Xia, Harbin Institute of Technology (China)

8907 1G Irradiance spatial non-uniformity correction in large-format infrared focal plane array measurement [8907-64]

H. Hua, Y. Li, X. Hu, Shanghai Institute of Technical Physics (China)

$89071 \mathrm{H} \quad$ Fusion of infrared and visible light images based on nonsubsampled shearlet transform [8907-65]

T. Zhang, Q. Zhou, H. Feng, Z. Xu, Q. Li, Y. Chen, Zhejiang Univ. (China)

$890711 \quad$ A new method to obtain ground control points based on SRTM data [8907-68]

P. Wang, W. An, X. Deng, X. Zhang, National Univ. of Defense Technology (China)

$89071 \mathrm{~L}$ The method of infrared polariametric imaging [8907-72]

Q. Zhou, H. Feng, Z. Xu, Q. Li, Y. Chen, Zhejiang Univ. (China)

$89071 \mathrm{M}$ A new method of NIR face recognition using kernel projection DCV and neural networks [8907-73]

Y. Qiao, Y. Lu, Y. Feng, F. Li, Y. Ling, Electronic Engineering Institute (China)

890710 Optical and mechanical structure design of a high altitude orbits collimating infrared earth simulator [8907-75]

Z. Wang, Changchun Univ. of Science and Technology (China); G. Zhang, Changchun Univ. of Science and Technology (China) and Jilin Engineering Research Ctr. of Photoelectric Measurement \& Control Instruments (China); Q. Chen, X. Sun, Changchun Univ. of Science and Technology (China); Y. Gao, Changchun Institute of Optics, Fine Mechanics and Physics (China)

8907 1Q High performance BGMI circuit for VLWIR FPAs [8907-79]

L. Hao, Shanghai Institute of Technical Physics (China) and Univ. of Chinese Academy of Sciences (China); H. Chen, A. Huang, J. Zhang, R. Ding, Shanghai Institute of Technical Physics (China)

8907 IR Research on method for generating infrared images of aerial target based on image synthesis [8907-80]

L. Wu, H. Yuan, New Star Research Institute of Applied Technology (China)

8907 is Tracking the key point of a building in infrared imaging guidance [8907-82] Y. Tan, F. Zhou, T. Jin, BeiHang Univ. (China)

8907 1T Design of a data transmission system based on gigabit ethernet [8907-83] Y. Yuan, L. Zhang, BeiHang Univ. (China); B. Xu, J. Wang, Changzhou Institute of Optoelectronic Technology (China); Y. Yuan, Changzhou Institute of Optoelectronic Technology (China) and Shanghai Institute of Technical Physics (China)

$89071 \mathrm{U}$ Detection algorithm based on spatial statistics for IR target [8907-84] S. Zuo, X. Meng, J. Liu, G. Liu, H. Li, Baicheng Ordnance Test Ctr. of China (China)

8907 1V Dynamic simulation for distortion image with furbulence atmospheric transmission effects [8907-85]

H. Du, J. Fei, D. Qing, H. Zhao, H. Yu, C. Cheng, Beijing Simulation Ctr. (China) 
8907 IW The simulation of turbulence effect based on the technology of optical wavefront control [8907-86]

H. Zhao, J. Fei, H. Du, H. Yu, J. Du, Beijing Simulation Ctr. (China); X. Hu, B. Dong, Beijing Institute of Technology (China)

8907 1X Verification of the Astronomical Almanac's algorithm for approximate the position of the sun [8907-91]

L. Zheng, G. Shen, J. Cai, East China Normal Univ. (China); Z. Dong, J. Gao, Shanghai Jiaotong Univ. (China)

$89071 \mathrm{Z}$ The research of moving object detection with a moving camera [8907-95]

H. Chen, G. Gu, Nanjing Univ. of Science and Technology (China); X. Bai, Science and Technology on Low-Light-Level Night Vision Lab. (China); T. Zhao, Xi'an Sicong Chuangwei Opto-Electronic Co., Ltd. (China); F. Xu, Nanjing Univ. of Science and Technology (China)

890720 Novel measurement method of infrared laser beam divergence angle based on two linear array CCDs [8907-99]

J. Xie, Huazhong Univ. of Science and Technology (China) and Huazhong Agricultural Univ. (China); H. Chen, Huazhong Univ. of Science and Technology (China); Z. Tan, D. Hou,

X. Wang, Huazhong Agricultural Univ. (China)

$890721 \quad$ Liquid dangerous goods detection based on electronic nose odor recognition technology [8907-100]

L. Sun, Northeastern Univ. (China)

890722 Study of jamming of the frequency modulation infrared seekers [8907-102]

F. Qian, Changchun Institute of Optics, Fine Mechanics and Physics (China) and Univ. of Chinese Academy of Sciences (China); J. Guo, Changchun Institute of Optics, Fine Mechanics and Physics (China); J. Shao, Changchun Institute of Optics, Fine Mechanics and Physics (China) and Univ. of Chinese Academy of Sciences (China); T. Wang, Changchun Institute of Optics, Fine Mechanics and Physics (China)

890723 A local image enhancement method based on adjacent pixel gray order-preserving principle [8907-103]

X. Fan, T. Cai, Shenyang Institute of Automation (China), Univ. of Chinese Academy of Sciences (China), Key Lab. of Optical-Electronics Information Processing (China), and Key Lab. of Image Understanding and Computer Vision (China); F. Zhu, Shenyang Institute of Automation (China), Key Lab. of Optical-Electronics Information Processing (China), and Key Lab. of Image Understanding and Computer Vision (China)

890724 Fabrication and performance of $1 \times 128$ linear PbS infrared focal plane array [8907-104] Z. Hou, J. Si, W. Wang, Y. Lv, J. Wang, X. Chen, Luoyang Optoelectro Technology Development Ctr. (China)

890725 Improved mean shift algorithm based on a dual patterns merging Robinson guard filter [8907-105]

F. Wang, Q. Chen, Nanjing Univ. of Science and Technology (China); Z. Miao, Science and Technology on Low-Light-Level Night Vision Lab. (China); T. Zhao, Xi'an Sicong Chuangwei Opto-Electronic Co., Ltd. (China); H. Chen, Nanjing Univ. of Science and Technology (China) 
890726 Morphological detection method with girdle structure [8907-107]

Y. Chen, Univ. of Electronic Science and Technology (China) and Luoyang Electronic Equipment Test Ctr. (China); G. Yan, Univ. of Electronic Science and Technology (China); Y. Huo, Luoyang Electronic Equipment Test Ctr. (China)

$890727 \quad$ IR characteristic simulation of city scenes based on radiosity model [8907-109]

X. Xiong, F. Zhou, X. Bai, X. Yu, BeiHang Univ. (China)

890728 An infrared and visible image SIFT registration based on MESR [8907-110] T. Gao, Y. XU, T. XU, Air Force Early Warning Academy (China); L. Shuai, Wuhan Univ. of Science and Technology (China)

890729 Numerical study on the influence of aluminum on infrared radiation signature of exhaust plume [8907-111]

W. Zhang, Q. Ye, S. Li, N. Wang, Beijing Institute of Technology (China)

8907 2A Evaluation of discrete sampling on thermal imaging systems [8907-114]

J. Wang, J. Cui, T. Bai, W. Jin, Z. Gao, Beijing Institute of Technology (China)

8907 2B Synthesized performance model of thermal imaging systems based on natural background [8907-116]

S. Chen, J. Wang, X. Wang, W. Jin, Beijing Institute of Technology (China)

8907 2C The technology of forest fire detection based on infrared image [8907-117]

Z. Wu, Changchun Institute of Optics, Fine Mechanics and Physics (China); G. Liu, Beijing Institute of Space Long March Vehicle (China); M. Wang, Changchun Institute of Optics, Fine Mechanics and Physics (China); S. Wang, Nanjing Institute of Electronics Technology (China)

8907 2D A new affine-invariant image matching method based on SIFT [8907-118]

P. Wang, Q. Chen, H. Chen, Nanjing Univ. of Science and Technology (China); H. Cheng, Z. Gong, Science and Technology on Low-Light-Level Night Vision Lab. (China)

8907 2E New detection algorithm for dim point moving target in IR-image sequence based on an image frames transformation [8907-119]

M. A. Mohamed, H. Li, Changchun Univ. of Science and Technology (China)

$89072 \mathrm{G}$ Experimental research on thermoelectric cooler for imager camera thermal control [8907-122]

B. Hu, A. Kang, X. Fu, S. Jiang, Shanghai Institute of Satellite Engineering (China); Y. Dong, Shanghai Academy of Spaceflight Technology (China)

$89072 \mathrm{H} \quad$ Research on infrared ship detection method in sea-sky background [8907-123]

D. Tang, G. Sun, D. Wang, Z. Niu, Z. Chen, National Univ. of Defense Technology (China)

890721 Error analysis and algorithm implementation for an improved optical-electric tracking device based on MEMS [8907-124]

H. Sun, Univ. of Shanghai for Science and Technology (China) and Shanghai Key Lab. of Modern Optical Systems (China); Q. WU, Univ. of Shanghai for Science and Technology (China) 
8907 2J A line mapping based automatic registration algorithm of infrared and visible images [8907-125]

R. Ai, Shenyang Institute of Automation (China), Univ. of Chinese Academy of Sciences

(China), and Key Lab. of Opto-Electronic Information Processing (China); Z. Shi, Shenyang Institute of Automation (China) and Univ. of Chinese Academy of Sciences (China);

D. XU, C. Zhang, Shenyang Institute of Automation (China), Univ. of Chinese Academy of Sciences (China), and Key Lab. of Opto-Electronic Information Processing (China)

8907 2K Calculation of signal-to-noise ratio (SNR) of infrared detection system based on MODTRAN model [8907-126]

X. LU, Xi'an Institute of Optics and Precision Mechanics (China) and Univ. of Chinese Academy of Sciences (China); C. Li, X. Fan, Xi'an Institute of Optics and Precision Mechanics (China)

$89072 \mathrm{M}$ The design and analysis of wide angle and broadband infrared antireflective film [8907-128]

J. Leng, Fudan Univ. (China) and Tianjin Jinhang Institute of Technical Physics (China); Y. Ji, H. Liu, K. Zhuang, D. Liu, Tianjin Jinhang Institute of Technical Physics (China)

$89072 \mathrm{~N} \quad$ A new algorithm of inter-frame filtering in IR image based on threshold value [8907-129] W. Liu, H. Leng, W. Chen, H. Yang, Q. Xie, B. Yi, H. Zhang, Xi'an Institute of Optics and Precision Mechanics (China)

890720 Influence of ejector technique on infrared radiation of the exhaust plume outside rectangular nozzle [8907-130]

Y. Feng, Y. LU, Y. Qiao, Electronic Engineering Institute (China)

8907 2P Preparation and properties on hollow nano-structured smoke material [8907-131] X. Liu, M. Dai, G. Fang, W. Shi, X. Cheng, H. Liu, T. Zhang, Research Institute of Chemical Defence (China)

$89072 Q \quad$ High-temperature target infrared spectrum radiance study [8907-132]

F. Xu, Shanghai Institute of Technical Physics (China) and Univ. of Chinese Academy of Sciences (China); Y. Hu, Shanghai Institute of Technical Physics (China); Q. Yin, Application Ctr. of Satellite Remote Sensing and Measurement in Shanghai (China); C. Gong, Shanghai Institute of Technical Physics (China); L. Zhu, H. He, China Resources Satellite Application Ctr. (China)

$89072 R \quad$ An improvement for scene-based nonuniformity correction of infrared image sequences [8907-133]

L. Geng, Q. Chen, Nanjing Univ. of Science and Technology (China); F. Shi, Science and Technology on Low-Light-Level Night Vision Lab. (China); C. Wang, Xi'an Sicong Chuangwei Opto-Electronic Co., Ltd. (China); X. Yu, Nanjing Univ. of Science and Technology (China)

890725 Infrared dim target detection based on image fusion [8907-134]

R. Hu, T. Wang, Huazhong Univ. of Science and Technology (China); G. Zhang, Luoyang Institute of Electro-Optical Equipment (China); G. Zhang, Huazhong Univ. of Science and Technology (China) 
8907 2T New scene-based adaptive bad pixel detection algorithm for IRFPA [8907-135] H. Leng, Z. Zhou, W. Liu, B. Yi, Q. Xie, D. Wu, J. Cao, Xi'an Institute of Optics and Precision Mechanics (China)

$89072 \mathrm{U} \quad$ Assembly and alignment of infrared refractive system [8907-136] L. Yang, J. Lin, Y. Wang, F. Chen, Shanghai Institute of Technical Physics (China)

8907 2V A method of infrared imaging missile's aerodynamic heating modeling and simulations [8907-137]

C. Cao, J. Xiang, X. Zhang, W. Wang, Luoyang Optoelectro Technology Development Ctr. (China)

8907 2W Image segmentation algorithm based on contourlet transform and background complexity [8907-138]

X. Li, Luoyang Optoelectro Technology Development Ctr. (China); W. Meng, J. Xiang, Luoyang Optoelectro Technology Development Ctr. (China) and Aviation Key Lab. of Science and Technology on Airborne Guided Weapons (China)

\section{Part Two}

$89072 \mathrm{X}$ Infrared transmission characteristic of indium-tin-oxide thin films prepared by femtosecond pulsed laser deposition [8907-139]

X. Zhu, W. Sun, F. Tao, X. Cao, X. Zhang, Luoyang Optoelectro Technology Development Ctr. (China)

$89072 Z$ Study on warning radius of diffuse reflection laser warning based on fish-eye lens [8907-145]

B. Chen, Changchun Univ. of Science and Technology (China); W. Zhang, Luoyang Electronic Equipment Test Ctr. (China)

890730 Biometric iris image acquisition system with wavefront coding technology [8907-147] S.-H. Hsieh, H.-W. Yang, S.-H. Huang, National Chiao Tung Univ. (Taiwan, China); Y.-H. Li, Feng Chia Univ. (Taiwan); C.-H. Tien, National Chiao Tung Univ. (Taiwan, China)

890731 Research on passivation of type II InAs/GaSb superlattice photodiodes [8907-150] L. Zhang, L. Zhang, X. Shen, X. Zhu, Z. Peng, Y. Lv, J. Si, W. Sun, Luoyang Optoelectro Technology Development Ctr. (China)

890733 Design of 10x uncooled thermal infrared zoom optical system [8907-152]

D. Mu, Y. Du, S. Mi, Y. Guo, Changchun Univ. of Science and Technology (China)

890734 The summary of Hilbert-Huang transform [8907-155]

S.-D. Song, Z. Yao, X.-N. Wang, Dalian Univ. of Technology (China)

890735 Mechanism design of continuous infrared lens [8907-157]

Y. Su, Changchun Institute of Optics, Fine Mechanics and Physics (China) and Univ. of Chinese Academy of Sciences (China); J. Zhang, T. LV, F. Yang, F. Wang, Changchun Institute of Optics, Fine Mechanics and Physics (China)

890736 Characteristics and optimization of radar target with plasma cover [8907-158]

Y. Yang, W. Zhao, W. Wang, X. Yi, J. Ji, X. Lin, Institute of Semiconductors (China) 
890737 Analysis of laser atmospheric propagation characteristic and optimization of laser rangefinder [8907-159]

W. Wang, Y. Yang, W. Zhao, X. Yi, J. Ji, X. Lin, Institute of Semiconductors (China)

890738 Color interpolation algorithm of CCD based on green components and signal correlation [8907-164]

$X$. Liang, Xi'an Institute of Optics and Precision Mechanics (China) and Univ. Of Chinese Academy of Sciences (China); W. Qiao, J. Yang, B. Xue, J. Qin, Xi'an Institute of Optics and Precision Mechanics (China)

8907 3A On-chip ADC for infrared focal plane arrays [8907-166]

L. Gao, G. Chen, P. Wang, R. Ding, Shanghai Institute of Technical Physics (China)

8907 3B Traceability study of optical fiber degree of polarization (DOP) measurement [8907-167] N. XU, J. Li, J. Li, Z. Zhang, National Institute of Metrology (China)

8907 3C Study on the volcanic ash cloud with Feng Yun-3 meteorological satellite data [8907-169] C. Gong, Shanghai Institute of Technical Physics (China); S. Jiang, Shanghai Institute of Technical Physics (China) and Univ. of Chinese Academy of Sciences (China); Y. Hu, P. Meng, Shanghai Institute of Technical Physics (China)

8907 3D Infrared image enhancement based on Riemann-Liouville fractional calculus and human visual properties [8907-170]

K. Zhang, Q. Hao, Y. Song, Y. Hu, Beijing Institute of Technology (China)

8907 3E Salient man-made structure detection in infrared images [8907-171]

D. Li, F. Zhou, T. Jin, BeiHang Univ. (China)

8907 3F A new infrared image processing method based on compressed sensing [8907-172] C. Mu, Xi'an Institute of Optics and Precision Mechanics (China) and Univ. Of Chinese Academy of Sciences (China); Y. Qiu, Z. Chen, Xi'an Institute of Optics and Precision Mechanics (China)

8907 3G Innovative design of a calibration mechanism for the space infrared detector [8907-176] D. Sun, B. Li, J. Liu, N. Ruan, Beijing Institute of Space Mechanics and Electricity (China)

8907 3H A high-speed and small-volume IR zoom lens using root-exchange theory and DOE element [8907-177]

L. Liu, X. Sun, X. Zhang, R. Li, North China Research Institute of Electro-optics (China)

890731 Extraction of optical rotation from chiral turbid medium with Mueller matrix decomposition [8907-180]

Y. Ma, P. Sun, Beijing Normal Univ. (China); W. Liu, Q. Yang, Q. Jia, Capital Normal Univ. (China)

8907 3J Interface design and properties in InAs/GaSb type-II superlattices grown by molecular beam epitaxy [8907-181]

Z. XU, Shanghai Institute of Technical Physics (China) and Univ. Of Chinese Academy of Sciences (China); J. Chen, F. Wang, Y. Zhou, Q. Xu, Shanghai Institute of Technical Physics (China); C. Jin, Shanghai Institute of Technical Physics (China) and Jinan Univ. (China);

L. He, Shanghai Institute of Technical Physics (China) 
8907 3K Super-resolution image reconstruction using iterative NEDI-based interpolation [8907-182] D. Yin, G. Wang, D. Kuang, Key Lab. of Infrared System Detection and Imaging Technology (China) and Shanghai Institute of Technical Physics (China)

8907 3L Dispersion and infrared jamming performance of hollow nanoshell smoke [8907-183] T. Zhang, X. D. Dai, L. N. Ren, L. Chen, M. Y. Dai, X. C. Liu, Y. Jiang, C. S. Chen, H. F. Liu, Research Institute of Chemical Defense (China)

$89073 \mathrm{M}$ Ship detection based on spatial partial features [8907-186]

H. Wang, F. Zhou, T. Jin, BeiHang Univ. (China)

$89073 \mathrm{~N} \quad$ Research of influence of oxidant on the photoelectric obscurity of artificial fog [8907-187]

M. Dai, X. Liu, H. Liu, C. Chen, T. Zhang, Research Institute of Chemical Defense (China)

890730 Design of the segmented primary optical telescope [8907-188]

K. Zhang, A. Yan, J. Cao, Z. Fan, L. Wu, Z. Zhang, Q. Zhu, Xi'an Institute of Optics and Precision Mechanics (China)

8907 3P Research of distortion rectification method for large vision angle IR imaging system [8907-189]

X. Zhang, WeiFang Univ. (China); Z. Ren, Z. Zhang, G. Sun, Tianjin Jinhang Institute of Technical Physics (China)

$89073 Q \quad$ A novel regularized edge-preserving super-resolution algorithm [8907-190] H. Yu, Huazhong Univ. of Science and Technology (China) and Huazhong Institute of Electro-Optics-Wuhan National Lab. for Optoelectronics (China); F. Chen, Z. Zhang, C. Wang, Huazhong Institute of Electro-Optics-Wuhan National Lab. for Optoelectronics (China)

8907 3T Vacuum packaging of InGaAs focal plane array with four-stage thermoelectric cooler [8907-195]

D. Mo, D. Liu, L. Yang, Q. Xu, X. Li, Shanghai Institute of Technical Physics (China)

8907 3U A new non-uniformity correction algorithm for IRFPA based on statistical properties of scene [8907-196]

B. Wang, Z. Liu, H. Qin, H. Zhou, R. Lai, S. Yang, H. Yu, Xidian Univ. (China)

8907 3V Infrared decoys recognition method based on geometrical features [8907-197]

S. Yang, B. Wang, S. Liu, H. Zhou, H. Qin, H. Yu, Z. Liu, Xidian Univ. (China)

8907 3W Estimate of the influence of muzzle smoke on function range of infrared system [8907-199] Y. Luo, J. Wang, J. Wu, J. Wu, M. Gao, F. Gao, Y. Zhao, L. Zhang, Xi'an Institute of Applied Optics (China)

$89073 X \quad$ The research of flexible and portable test system for focal-plane-array chips [8907-201] B. XU, Shanghai Institute of Technical Physics (China) and Univ. of Chinese Academy of Sciences (China); Y. Yuan, X. Li, Shanghai Institute of Technical Physics (China) 
$89073 Y$ Thermal annealing effects on the properties of intersubband absorption in CdS/ZnSe and (CdS/ZnSe)/BeTe II-VI quantum wells [8907-202]

B.-S. Li, Harbin Institute of Technology (China); R. Akimoto, National Institute of Advanced Industrial Science and Technology (Japan); A. Shen, The City College of New York (United States)

$89073 Z$ The electrochemical capacitance-voltage characterization of InP based p-i-n structures [8907-203]

L. Wang, Y. Lu, Shanghai Institute of Technical Physics (China) and Univ. of Chinese Academy of Sciences (China); J. XU, X. Li, Shanghai Institute of Technical Physics (China)

890740 Image reconstruction by multiscale compressed sensing based on a new transform [8907-210]

C. Hu, S. Guo, Yanshan Univ. (China)

890741 Fabrication and performance of InAs/GaSb type-II superlattices mid-wavelength infrared detectors [8907-211]

L. Yang, J. Deng, Beijing Univ. of Technology (China); Y. Shi, Kunming Institute of Physics (China); Y. Chen, B. Wu, Beijing Univ. of Technology (China)

890742 Properties study of ZnS thin films deposited on HgCdTe substrate by different methods [8907-212]

P. XU, G. XU, Shanghai Institute of Technical Physics (China) and Univ. of Chinese Academy of Sciences (China); K. Chu, Shanghai Institute of Technical Physics (China);

N. Wang, Shanghai Institute of Technical Physics (China) and Univ. Of Chinese Academy of Sciences (China); Q. Zhou, Shanghai Institute of Technical Physics (China);

Y. Tang, Shanghai Institute of Technical Physics (China) and Univ. of Chinese Academy of Sciences (China); K. Zhang, X. Li, Shanghai Institute of Technical Physics (China)

890743 Jamming effectiveness analysis of IR smoke projectile based on sight optical observation [8907-213]

L. Wang, Z. Liu, F. Wang, Dalian Naval Academy (China)

890744 Design and implementation of Gm-APD array readout integrated circuit for infrared 3D imaging [8907-214]

L. Zheng, J. Yang, Z. Liu, H. Dong, J. Wu, W. Sun, Southeast Univ. (China)

$890745 \quad$ New multimodal image registration method based on moving targets' trajectory [8907-216] H. Yu, B. Wang, S. Liu, H. Zhou, H. Qin, S. Yang, Z. Liu, Xidian Univ. (China)

890746 MTF measurement of IRFPA based on double-knife edge scanning method [8907-217] C. Ying, China Electronics Technology Group Corp. (China); B. Wu, China Electronics Technology Group Corp. (China) and Science and Technology on Electronic Test \& Measurement Lab. (China); H. Wang, China Electronics Technology Group Corp. (China); X. Shi, China Electronics Technology Group Corp. (China) and Science and Technology on Electronic Test \& Measurement Lab. (China); H. Liu, China Electronics Technology Group Corp. (China)

890747 Design method of ARM based infrared camouflage target recognition system [8907-218] Y. Wang, H. Shen, G. Li, Mechanical Engineering College (China) 
ROIC for gated 3D imaging LADAR receiver [8907-221]

G. Chen, Shanghai Institute of Technical Physics (China) and Univ. of Chinese Academy of Sciences (China); J. Zhang, Shanghai Institute of Technical Physics (China);

P. Wang, J. Zhou, L. Gao, Shanghai Institute of Technical Physics (China) and Univ. of Chinese Academy of Sciences (China); R. Ding, Shanghai Institute of Technical Physics (China)

890749 Thermal cycling reliability of indirect hybrid HgCdTe infrared detectors [8907-223] X. Chen, K. He, J. Wang, Q. Zhang, Shanghai Institute of Technical Physics (China)

8907 4A An electrically controlled liquid crystal Fabry-Perot hyperspectral imaging chip in midinfrared region [8907-225]

A. Fu, H. Zhang, X. Zhang, H. Sang, C. Xie, Huazhong Univ. of Science and Technology (China)

8907 4B Vibration characteristics of aluminum material and its influences on laser Doppler voice acquisition [8907-228]

Y. Zhang, L. Li, Y. Tong, H. Zeng, Y. Zhou, Institute of Semiconductors (China)

8907 4C Research of polarization imaging detection method for water surface target in foggy weather [8907-229]

F. Wang, C. Yin, Y. Wang, New Star Research Institute of Applied Technology (China)

8907 4D The optical axis optimization in measurement of decentration of lens [8907-230]

Y. Wang, L. Yang, C. Wang, Shanghai Institute of Technical Physics (China)

8907 4E An inverter-based capacitive trans-impedance amplifier readout with offset cancellation and temporal noise reduction for IR focal plane array [8907-231]

H.-H. Chen, C.-C. Hsieh, National Tsing Hua Univ. (Taiwan, China)

$89074 \mathrm{~F} \quad$ A dual-channel fusion system of visual and infrared images based on color transfer [8907-232]

C. Pei, X. Jiang, P. Zhang, H. Liang, Academy of Armored Force Engineering (China)

8907 4G A new polarization image fusion method based on Choquet fuzzy integral [8907-233] H. Yuan, Q. Huang, G. Xu, C. Yin, New Star Research Institute of Applied Technology (China)

$89074 \mathrm{H} \quad$ Phase transfer function based method to alleviate image artifacts in wavefront coding imaging system [8907-236]

X. Mo, Anhui Univ. of Technology (China); J. Wang, Tianjin Univ. (China)

89074 Experiment research on infrared targets signature in mid and long IR spectral bands [8907-237]

C. Wang, P. Hong, B. Lei, S. Yue, Z. Zhang, Huazhong Institute of Electro-Optics-Wuhan National Lab. for Optoelectronics (China); T. Ren, Jiuzhiyang Infrared System Co., Ltd. (China)

8907 4J Application of physical optics to ocean surface radar scattering with CUDA [8907-238] L. Ling-Hu, Z. Wu, X. Guo, Xidian Univ. (China) 
8907 4K Study on effect of SNR and fill factor on faint target signature quantitative measurement [8907-239]

Z. Liu, H. Mao, Y. Dai, Science and Technology on Optical Radiation Lab. (China)

$89074 \mathrm{~L}$ The design of a switchable dual-field-of-view thermal optical system [8907-240]

T. Zhang, Z. Liao, Beijing Institute of Space Mechanics and Electricity (China)

$89074 \mathrm{M} \quad$ Research on enhancing performance of laser warning systems utilizing microlens array [8907-242]

X. Shao, P. Han, F. Liu, Xidian Univ. (China)

8907 4N Hybrid regularization image restoration algorithm based on total variation [8907-245]

H. Zhang, Y. Wang, Chongqing Univ. of Technology (China)

890740 Research on compressive imaging technology based on image blocking [8907-246]

Z. Zhang, S. Ding, Academy of Armored Force Engineering (China)

8907 4P Radiometric calibration of the three-channel imaging polarimeter [8907-247]

L. Zhang, X. Liu, C. Yin, X. Luo, C. Duan, New Star Research Institute of Applied Technology (China)

$89074 Q \quad$ Target detection based on polarization imaging under bad illumination conditions [8907-249]

Y. Han, B. Mao, Y. Wang, New Star Research Institute of Applied Technology (China)

$89074 R$ Analysis of high frame rate readout circuit for near-infrared InGaAs focal plane array [8907-250]

Z. Huang, Y. Chen, S. Huang, J. Fang, Shanghai Institute of Technical Physics (China)

89074 Development of the electronics system prototype of the panoramic camera for space applications [8907-254]

Y.-Q. Duan, Xi'an Institute of Optics and Precision Mechanics (China) and Univ. of Chinese Academy of Sciences (China); W. Gao, W.-D. Qiao, J.-F. Yang, D.-S. Wen, Xi'an Institute of Optics and Precision Mechanics (China)

8907 4T On an adaptive scene-based gray super-resolution technique of infrared focal plane array imaging system [8907-258]

M. He, T. Zhang, W. Liu, C. Zhang, Air Defense Forces Academy (China); J. Zhang, Zheng Zhou Automation Institute (China)

$89074 \mathrm{U}$ Development of the control circuits for the TID-CCD stereo camera of the Chang'E-2 satellite based on FPGAs [8907-259]

Y.-Q. Duan, Xi'an Institute of Optics and Precision Mechanics (China) and Univ. of Chinese Academy of Sciences (China); W. Gao, W.-D. Qiao, D.-S. Wen, B.-C. Zhao, Xi'an Institute of Optics and Precision Mechanics (China)

$89074 \mathrm{~V}$ Adaptive non-uniformity correction method based on temperature for infrared detector array [8907-260]

Z. Zhang, S. Yue, P. Hong, G. Jia, B. Lei, Huazhong Institute of Electro-Optics-Wuhan National Lab. for Optoelectronics (China) 
$89074 \mathrm{~W}$ Research on inverse method of near sea surface atmosphere aerosol parameters [8907-261]

K. Wu, Z. Liu, J. Wu, H. Mao, Science and Technology on Optical Radiation Lab. (China)

8907 4X Infrared image quality evaluation method without reference image [8907-262] S. Yue, Huazhong Institute of Electro-Optics-Wuhan National Lab. for Optoelectronics (China); T. Ren, Jiuzhiyang Infrared System Co., Ltd. (China); C. Wang, B. Lei, Z. Zhang, Huazhong Institute of Electro-Optics-Wuhan National Lab. for Optoelectronics (China)

$89074 Z$ A color inheritance image fusion method based on histogram matching [8907-264] B. Wang, X. Jin, J. Han, Y. Zhang, L. Bai, Nanjing Univ. of Science and Technology (China)

890750 Design of the in-situ testing system for the accelerated life test of the space infrared device [8907-266]

X. Zhu, Shanghai Institute of Technical Physics (China) and Univ. of Chinese Academy of Sciences (China); H. Zhang, Y. Wang, X. He, H. Gong, Shanghai Institute of Technical Physics (China)

$890751 \quad$ Effect of $Y$ irradiation on the performance of InGaAs infrared detectors [8907-267] X. Huang, T. Li, X. Shao, X. Li, H. Gong, Shanghai Institute of Technical Physics (China) and Key Lab. of Infrared Imaging Materials and Detectors (China)

890752 Research on object detection based on circular polarization property [8907-268] Y. Wu, X. Zeng, C. Yin, X. Luo, New Star Research Institute of Applied Technology (China)

890753 Effect of InGaAs strain reducing layer and rapid thermal annealing on the properties of InAs/GaAs quantum [8907-269]

D. Shi, Changchun Univ. of Science and Technology (China); M. You, Aviation Univ. of Air Force (China); Z.-G. Li, G. Liu, L. Li, Z. Qiao, X. Ma, Changchun Univ. of Science and Technology (China)

890754 Research of detecting details and features of infrared polarization imaging experiment [8907-270]

F. Yang, X. Liu, J. Wang, New Star Research Institute of Applied Technology (China)

890755 Research of extended-wavelength $64 \times 64 \operatorname{In}_{0.83} \mathbf{G a}_{0.17 A s}$ focal plane arrays [8907-275] M. Shi, Shanghai Institute of Technical Physics (China) and Univ. of Chinese Academy of Sciences (China); T. Li, X. Shao, X. Li, H. Gong, Shanghai Institute of Technical Physics (China)

890756 Calculation of scattering characteristic of complex target on multi-core platform [8907-277]

X. Guo, Z. Wu, L. Linghu, Xidian Univ. (China)

890757 Ray-tracing algorithm based on BRDF [8907-279]

L. Zheng, H. Mao, K. Wu, Science and Technology on Optical Radiation Lab. (China)

890758 Design and analysis of a novel self-deployable baffle [8907-282]

K. Du, K. Yin, Institute of Optics and Electronics (China) and Univ. of Chinese Academy of Sciences (China); H. Li, S. Liao, Institute of Optics and Electronics (China); F. Long,

PanGang Group Research Institute Co., Ltd. (China) 
8907 5A Dark current characterization and simulation for In 0.78 Ga $a_{0.22}$ As PIN photodetectors [8907-286]

B. Liu, X. Ji, Y. Liao, F. Yan, Nanjing Univ. (China); H. Tang, X. Li, H. Gong, Shanghai Institute of Technical Physics (China)

$89075 \mathrm{~B}$ Research on detection of high-temperature $\mathrm{CO}_{2}$ with infrared spectrum from space [8907-292]

J. Wu, Z. Liu, H. Mao, Y. Dong, Science and Technology on Optical Radiation Lab. (China)

8907 5C Infrared-visual image sequence fusion algorithm with noise suppression [8907-294]

$X$. Wang, Changchun Univ. of Technology (China) and Jilin Univ. (China); F. Liu, Jilin Univ.

(China); Y. Wei, H. Zhou, Changchun Univ. of Technology (China)

8907 5D Complicated spatial multi sensor system integrated on adaptive technique [8907-295]

C. Guo, Q. Ding, Luoyang Institute of Electro-Optical Equipment (China); L. Zhou, Beijing Institute of Technology (China); H. Liu, Luoyang Institute of Electro-Optical Equipment (China)

$89075 \mathrm{E}$ Ice flood detection based on pulse coupled neural network [8907-296]

X. Liu, Z. Chen, W. Wang, Mechanical Engineering College (China)

8907 5F Polarization imaging detection technology research [8907-298]

M. Xue, F. Wang, G. Xu, H. Yuan, New Star Research Institute of Applied Technology (China)

890756 A low-power small-area ADC array for IRFPA readout [8907-299]

S. Zhong, L. Yao, Kunming Institute of Physics (China)

$89075 \mathrm{H} \quad$ A local-sky star recognition algorithm based on rapid triangle pattern index for ICCD images [8907-301]

W. Zhang, Tianjin Jinhang Institute of Technical Physics (China); S. Qi, Huazhong Univ. of Science and Technology (China); R. Zhang, L. Yang, J. Sun, L. Song, Tianjin Jinhang Institute of Technical Physics (China); J. Tian, Huazhong Univ. of Science and Technology (China)

$890751 \quad$ Infrared image superframing technique based on high-speed digital transmission circuit [8907-302]

W. Hong, L. Yao, R. Ji, C. Liu, Kunming Institute of Physics (China)

8907 5J Design and simulation of electrically addressed infrared filtering chip based on cascaded liquid-crystal Fabry-Perot effect for integration application of infrared spectral imaging sensor array [8907-303]

H. Zhang, A. Fu, X. Zhang, H. Sang, C. Xie, Huazhong Univ. of Science and Technology (China)

$89075 \mathrm{~K}$ The calculation model of the satellite solar panels infrared feature [8907-304]

L. Yang, X. Lv, W. Jin, H. Yang, J. Zhao, Electronic Engineering Institute (China)

$89075 \mathrm{~L}$ The lifetime prediction model of stirling cryocooler for infrared detector assembly [8907-310]

S. Yang, China Electronic Product Reliability and Environmental Testing Research Institute (China); X. Liu, Y. Wu, Shanghai Institute of Technical Physics (China) 
$89075 \mathrm{M}$ Star sub-pixel centroid calculation based on multi-step minimum energy difference method [8907-313]

D. Wang, People's Liberation Army (China) and Navy Aeronautical and Astronautical Univ. (China); Y. Han, Navy Aeronautical and Astronautical Univ. (China); T. Sun, People's Liberation Army (China)

Author Index 


\title{
Conference Committee
}

\author{
Conference Chairs
}

Konstantin Vodopyanov, Stanford University (United States) and CREOL, The College of Optics and Photonics, University of Central Florida (United States)

Jin Guofan, Tsinghua University (China)

Songlin Zhuang, University of Shanghai for Science and Technology (China)

Local Organizing Committee

Jiaqi Wang, Changchun Institute of Optics, Fine Mechanics and Physics (China)

Zuyan Xu, Technical Institute of Physics and Chemistry (China)

Zunqi Lin, Shanghai Institute of Optics and Fine Mechanics (China)

Dianyuan Fan, Shanghai Institute of Optics and Fine Mechanics (China)

Jingshan Jiang, Center for Space Science and Applied Research (China)

Liwei Zhou, Beijing Institute of Technology (China)

Shouhuan Zhou, North China Research Institute of Electro-optics (China)

Desheng Jiang, Wuhan University of Technology (China)

Jianquan Yao, Tianjin University (China)

Qingxi Tong, Institute of Remote Sensing and Digital Earth (China)

Junhao Chu, Shanghai Institute of Technical Physics (China)

Yongqi Xue, Shanghai Institute of Technical Physics (China)

Program Committee

Junhao Chu, Chair, Shanghai Institute of Technical Physics (China)

Jinxue Wang, Chair, Raytheon Company (United States)

Min Gu, Swinburne University of Technology (Australia)

Andreas Tünnermann, Friedrich-Schiller-Universität Jena (Germany)

Connie Chang, University of California, Berkeley (United States)

Shibin Jiang, AdValue Photonics Inc. (United States)

H. C. Liu, Shanghai Jiao Tong University (China)

Xiaocong Yuan, Nankai University (China)

Wei Shi, Tianjin University (China)

Min Qiu, Zhejiang University (China)

Nanjian Wu, Institute of Semiconductors (China) 
Session Chairs

Infrared Imaging and Applications

Jeffery J. Puschell, Raytheon Space Airborne Systems (United States)

Jens Nieke, European Space Agency (Germany)

Haimei Gong, Shanghai Institute of Technical Physics (China)

Zelin Shi, Shenyang Institute of Automation (China)

Qian Chen, Nanjing University of Science and Technology (China)

Jin Lu, Tianjin Jinhang Institute of Technology Physics (China) 


\section{Introduction}

We have had the great honor of organizing the Fifth International Symposium on Photoelectronic Detection and Imaging (ISPDI) in Beijing. It was truly a great pleasure for us to greet the more than 1,200 participants from many different countries attending ISPDI 2013! I firmly believe that the symposium will become an important international event in the field of photoelectronic detection and imaging technology.

ISPDI 2013 was sponsored by SPIE, The Optical Society, European Optical Society, and the Chinese Society of Astronautics, and was organized by the Photoelectronic Technology Committee, Chinese Society of Astronautics, Tianjin Jinhang Institute of Technical Physics, Science and Technology on Low Light Level Night Vision Laboratory, Science and Technology on Optical Radiation Lab. and Science and Technology on Electromagnetic Scattering Lab. There were 26 cooperating organizations that supported the meeting. Nearly 850 papers were accepted for presentation at ISPDI 2013, contributed by over 1,370 authors from more than 10 countries, including the United States, United Kingdom, Germany, France, Norway, Australia, Canada, Japan, Korea, Russia, China, and so on. We had seven plenary speeches and 135 famous scientists and experts from home and abroad to present the invited talks at 10 different conferences.

The purpose of ISPDI 2013 is to provide a forum for the participants to report and review the innovative ideas and up-to-date progress and developments, and discuss the novel approaches to applications in the field of photoelectronic detection and imaging. It is sincerely hoped that the research and developments in optical and photoelectronic fields will be promoted, and that international cooperation and the sharing of common interests will be enhanced.

On behalf of Prof. Konstantin Vodopyanov, and the other conference chairs, and the Organization Committee of ISPDI, I would like to heartily thank our sponsors and cooperating organizations for all they have done for the meeting. Thanks also to all the authors for their contributions to the proceedings, to all of the participants and friends for their interest and efforts in helping us make the symposium possible, to the Program Committee for their effective work and valuable advice, and especially the ISPDI 2013 Secretariat and the SPIE staff for their tireless effort and outstanding service in preparing the meeting and publishing the conference proceedings.

Guofan Jin 